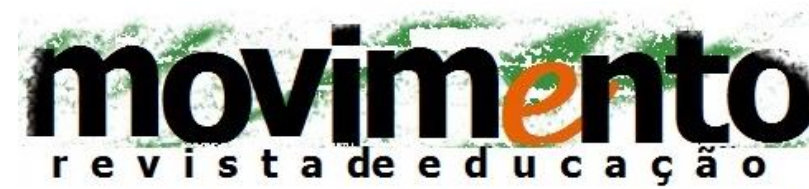

faculdade de educação - programa de pós-graduação em educação

universidade federal fluminense

issn 2359-3296

ano 3 número 4 - 2016

\section{POLÍTICAS DE CURRÍCULO E SISTEMA DE AVALIAÇÃO EXTERNA: disputas pela autonomia docente}

\author{
Rodrigo Mendonça dos Santos ${ }^{1}$ \\ Sandra Lúcia Escovedo Selles²
}

\section{ResUmo}

Esse artigo examina algumas das relações entre as políticas curriculares e de avaliação externa do Estado do Rio de Janeiro estabelecendo diálogos com experiências vividas por dois professores de Biologia da rede estadual de ensino. Utilizando referenciais do campo do currículo e da história da educação e mobilizando memórias destes professores, os quais produziram narrativas sobre suas experiências cotidianas com o Currículo Mínimo e as avaliações legisladas pela Secretaria de Educação do Estado do Rio de Janeiro (SEEDUC-RJ), o artigo discute as tensões que envolvem o emprego dessas políticas e a autonomia docente no ambiente profissional.

Palavras-chave: Currículo mínimo, avaliação externa, autonomia docente.

\section{ABSTRACT}

This article analyses the relation between curriculum and external exams policies on education in the State of Rio de Janeiro creating connections with the experiences lived by two Biology teachers. References on curriculum and history of education and memories of these teachers, which produced narratives about their daily experiences with the Currículo Mínimo and the external exams executed by the state education department (SEEDUC), were used to discuss the tensions involving these policies and teaching autonomy in schools.

Keywords: Curriculum, external examination, teaching autonomy.

\footnotetext{
1 Licenciado em Ciências Biológicas, Mestrando do Programa de Pós-Graduação em Educação da Universidade Federal Fluminense Professor da rede estadual do Rio de Janeiro e. E-mail: rod3078@gmail.com

${ }^{2}$ Doutora em Educação em Ciências. Professora da Faculdade de Educação e do Programa de Pós-Graduação em Educação da Universidade Federal Fluminense. E-mail: escovedoselles@gmail.com
} 


\section{INTRODUÇÃO}

O ambiente escolar é atravessado por diversas políticas educacionais, que são frequentemente produzidas à revelia da escola, controlando e regulando o trabalho docente, a organização, a administração e, naturalmente, o ensino que se realiza nesta instituição. Essa ingerência sobre a instituição escolar vai ao encontro das ideias de Edward Thompson (1981) quando associa as ações humanas à estrutura social na qual estas se produzem, o que permite compreender que esta correlação estabelece e impõe limites às ações criativas de homens e mulheres na história, nelas incluindo os sujeitos que integram a comunidade escolar. Nesta direção, no presente artigo, as reflexões focalizam não apenas as restrições que envolvem o trabalho do professor, mas também o potencial docente para manter autonomia (ainda que relativa) sobre seu trabalho, mesmo que este esteja a todo o momento sendo atravessado por políticas educacionais que pretendem controlá-lo ou regular seu comportamento.

Ainda que as políticas interfiram sobre o fazer docente e sobre as ações empreendidas pela escola, as possibilidades de que dispõem os professores de dirigir sua prática não podem ser desprezadas. Segundo Maurice Tardif (2014), os "professores de profissão" destacam como fonte primeira de sua competência, a fonte privilegiada do seu saber-ensinar, em outras palavras sua experiência profissional. Neste artigo, ao estudar algumas das políticas que atravessam o trabalho docente na escola, e ao ouvir depoimentos de professores, esta fonte privilegiada é mobilizada a partir das memórias e das narrativas que os docentes produzem. Ao narrarem suas experiências, mobilizando suas memórias, os docentes tornam públicas as experiências únicas vivenciadas no ambiente escolar e que podem contribuir para o entendimento de algumas questões educacionais que se tornam agudas no contexto atual em nosso país. 
Em especial, examinamos neste trabalho, as tensões entre as políticas curriculares, em particular o Currículo Mínimo, e de avaliação do governo do Governo do Estado do Rio de Janeiro e o trabalho docente em sala de aula. Para isso, a análise se configura a partir de entrevistas realizadas com dois professores de Biologia da Rede Estadual do Rio de Janeiro visando compreender relações entre essas políticas e a autonomia do trabalho docente.

\section{Currículo Mínimo, SaerJ-SaerJinho e Autonomia Docente}

Desde fevereiro de 2011, a Secretaria de Educação do Estado do Rio de Janeiro (SEEDUC) estabelece o Currículo Mínimo aos docentes e discentes das instituições estaduais de ensino afim de "orientar, de forma clara e objetiva, os itens que não podem faltar no processo ensino-aprendizagem, em cada disciplina, ano de escolaridade e bimestre." ${ }^{3}$ Dessa forma, cada uma das disciplinas ministradas nas escolas estaduais do Rio de Janeiro possui atualmente uma extensa lista de habilidades e competências que estabelecem os conhecimentos mínimos a serem apreendidos pelos discentes em cada bimestre do ano letivo.

Concomitantemente, em abril de 2011, a SEEDUC deu início ao SAERJ (Sistema de Avaliação Da Educação Básica do Estado do Rio de Janeiro). Esse sistema é composto por uma avaliação bimestral, o Saerjinho e uma avaliação aplicada no final de cada ano, o SAERJ. Segundo a SEEDUC, o Saerjinho tem como objetivo "acompanhar mais de perto o rendimento dos estudantes, detectando de maneira mais ágil e fiel as dificuldades de aprendizagem"4. Segundo o portal "Conexão Professor", desenvolvido pela SEEDUC, e voltado para professores e diretores da rede estadual, os resultados da avaliação em cada bimestre apontam "a eficiência e a qualidade do trabalho desenvolvido em cada unidade escolar e serão aproveitados nas

\footnotetext{
${ }^{3} \mathrm{http} / / /$ www.rj.gov.br/web/seeduc/exibeconteudo?article-id=759820 . Acesso em 18/08/2014. ${ }^{4} \mathrm{http}: / /$ www.conexaoprofessor.rj.gov.br/saerj.asp . Acesso em 18/08/2014.
} 
diversas instâncias do sistema de ensino" e, a partir dos resultados, "será possível, por exemplo, ajustar as práticas docentes à realidade dos estudantes e traçar políticas públicas de melhoria da qualidade da Educação Básica" 5 . Os resultados do SAERJ, por sua vez, servem para compor um índice, o IDERJ Índice de Desenvolvimento da Educação do Estado do Rio de Janeiro. Essas avaliações são organizadas por meio de uma matriz de referência que estabelece competências e habilidades de maneira semelhante ao que ocorre no Currículo Mínimo.

Esses dispositivos legais da SEEDUC, que desde então passaram a intervir sobre o currículo escolar, condizem com uma modalidade de racionalização do trabalho docente que vêm se tornando mais aguda - ou mais "refinada" - nas últimas décadas. Para Jose Contreras (2012), a determinação cada vez mais detalhada do currículo, além de projetos curriculares que estipulam o que o professor deve fazer, reflete a intensa racionalização tecnológica pela qual passa o ensino, e através da qual o docente, cada vez mais, perde de vista 0 controle sobre suas tarefas. Michael Apple $(1995 ; 1996)$ é outro autor cujas ideias enfatizam que o declínio da autonomia em decisões pedagógicas é maior na medida em que o controle por parte do Estado sobre o trabalho de ensinar aumenta. Nesse processo, conforme também sustenta António Nóvoa (1997), amplia-se a distância entre aqueles que tomam as decisões e os atores da educação.

Ao mobilizar o conceito de performatividade, as análises efetuadas por Stephen Ball (2004) sobre as políticas educacionais em diferentes países enriquecem o exame das relações entre as determinações curriculares do estado do Rio de Janeiro. $O$ autor considera que a performatividade desempenha um papel importante nesse conjunto de novas políticas educacionais tomadas ao redor de todo o mundo. A performatividade é entendida por ele como uma tecnologia, uma cultura, um modo de regulação que utiliza comparações, exposições e críticas para controlar, incentivar e alterar (BALL, 2002). A cultura de

${ }^{5}$ http://www.conexaoprofessor.rj.gov.br/saerj.asp . Acesso em 18/08/2014. 
performatividade permite que o estado se insira profundamente nas práticas e subjetividades das instituições e de seus trabalhadores, produzindo novos significados e novos perfis. Para Ball, essa tecnologia política não serve apenas para reforma educacional, mas também opera como mecanismo que reforma os professores e a própria concepção do que é ser professor.

A utilização cada vez mais difundida do binômio currículo-avaliação parece representar significativamente $\mathrm{o}$ avanço desse processo de racionalização e performatividade do ensino no Estado do Rio de Janeiro, em particular, e no Brasil, em geral. O primeiro elemento desse binômio, o Currículo Mínimo, estabelece o que deve ser ensinado durante as aulas. O segundo, as avaliações SAERJ e Saerjinho, visam aferir se os objetivos propostos no currículo estão sendo alcançados, pretendendo garantir a execução do primeiro. Ou seja, as avaliações externas vêm sendo utilizadas com a justificativa de medir a qualidade do ensino, para identificar erros e corrigir desvios nas práticas. Por meio da vinculação estreita entre currículo e avaliação no quadro educacional do estado do Rio de Janeiro, reduzem-se drasticamente as possibilidades inventivas por parte dos docentes em seu cotidiano, ameaçando a autonomia docente.

Os estudos de Elizabeth Macedo (2014) trazem elementos importantes para a reflexão sobre o caso do estado do Rio de Janeiro. A autora, apoiada nas teorias do discurso de Laclau e Mouffe (2004), entende as políticas curriculares como discursos hegemônicos que fixam sentidos para a educação. A definição de hegemonia para esses autores é a operação pela qual um significado assume o lugar da totalidade. Macedo defende que as políticas têm tomado a "qualidade da educação" como significante capaz de sobredeterminar as demandas de diferentes grupos que se constituem no jogo político. Independente do espectro político que ocupam, todos defendem uma educação de qualidade, ao mesmo tempo em que grupos políticos distintos se constituem no processo de significar a qualidade da educação. 
Ao que se pode compreender, as discussões sobre sentidos de qualidade de educação circulam sobre o contexto educacional, como justificativas plausíveis para a introdução de políticas tais como as que são examinadas neste artigo. Afinal, quem haveria de discordar que o sistema educacional do estado deve ser de qualidade? Entretanto, é preciso desconfiar da retórica que acompanha as finalidades educacionais listadas no currículo mínimo, ou mesmo que seja possível "definir" o que seria essa "qualidade". Luiz Dourado e João de Oliveira (2009) afirmam que a discussão da qualidade da educação remete à definição do que se entende por educação. Ainda que seja inviável operar com uma definição sobre educação, caberia indagar se a escola se restringe às diferentes etapas de escolarização que se apresentam de modo sistemático por meio do sistema escolar? Ou devemos ir além e entendê-la também como espaço múltiplo e institucional de produção e de disseminação do saber historicamente produzido pela humanidade? Portanto, as diferentes formas de compreensão da função social da escola levam à produção de definições distintas sobre a qualidade escolar.

Ademais, cabe realçar que a vinculação entre as políticas curriculares e de avaliação do estado do Rio de Janeiro se encontra comprometida com a produção de estatísticas que exibam o alcance da solução de problemas do sistema educacional deste estado. Segundo Thomas S. Popkewitz o uso de números na criação de um espaço de equivalência pelo qual se possa julgar, avaliar e ordenar práticas fabricam tipos específicos de individuos (POPKEWITZ, 2013). Assim, além de serem questionáveis quanto a sua capacidade para mensurar a qualidade do ensino, essas modalidades de avaliações e rankings criados de fora para dentro da escola, categorizam os bons e maus alunos e também os bons e maus professores, indicando as práticas que são desejáveis e as não desejáveis.

No contexto empírico desta pesquisa, a busca pela melhoria na qualidade do ensino por parte do Governo do Estado do Rio de Janeiro está diretamente ligada ao ajuste das práticas docentes, como deixa claro a passagem 
anteriormente citada, presente no portal de apresentação da avaliação externa atualmente utilizada: "[...] será possível, por exemplo, ajustar as práticas docentes à realidade dos estudantes e traçar políticas públicas de melhoria da qualidade da Educação Básica. "6

Com base nessas reflexões, no presente artigo buscamos compreender, tomando como base as experiências narradas pelos professores, como essas políticas do estado do Rio vêm influenciando a autonomia de seu trabalho em sala de aula.

\section{EXPERIÊnCIAs Docentes com Políticas CuRRICULARES}

Para analisar as tensões entre as políticas curriculares e de avaliação com a autonomia docente, as memórias de dois professores de Biologia são mobilizadas, neste artigo, como fonte de pesquisa de modo a sustentar uma discussão sobre suas experiências com as políticas curriculares e de avaliação da rede estadual de ensino do Rio de Janeiro. Neste intento, as reflexões de Thomson (1997) são valiosas, pois o autor assinala que as narrativas podem possibilitar a análise dos significados subjetivos das experiências vividas e a natureza da memória individual e da memória coletiva. Assim, ao ouvir o que os professores têm a dizer sobre o seu trabalho pretende-se compreender tensões e disputas que envolvem o ambiente escolar por meio da narrativa de suas experiências com as políticas em questão.

A opção pelo uso de depoimentos orais também se apoia em Andrè Chervel (1990) quando nos alerta para a necessidade de não considerar apenas os documentos oficiais como a expressão do que ocorre no cotidiano escolar, marcando as distinções entre "finalidades de objetivo" e "finalidades reais". O autor distingue as "finalidades de objetivo", presentes nos documentos oficiais, das "finalidades reais", incorporadas pelos docentes nas instituições, e afirma

${ }^{6}$ http://www.conexaoprofessor.rj.gov.br/saerj.asp . Acesso em 18/08/2014. 
que um documento oficial geralmente é produzido principalmente para "modificar ou suprimir certas práticas, do que sancionar oficialmente uma realidade" (ibid., p. 190). De acordo com Chervel,

[...] as finalidades de ensino não estão todas forçosamente inscritas nos textos. Assim, novos ensinos às vezes não precisam ser explicitamente formulados para serem introduzidos nas salas de aula. Além disso, pode-se perguntar se todas as finalidades inscritas nos textos são de fato finalidades "reais". (CHERVEL, 1990, p. 189).

A reflexão de Chervel, ainda que dirigida à produção do conhecimento escolar, produzido no interior da instituição escolar, parece também oportuna para o exame das relações entre currículo mínimo, avaliação e autonomia docente, objeto deste artigo. Com efeito, apenas a análise dos documentos escritos que explicitam as finalidades do currículo mínimo e da adoção das avaliações no interior das escolas pode fragilizar nosso entendimento sobre essas relações. Ao optar pelo emprego das narrativas dos docentes ao mobilizar suas memórias acerca de suas vivências curriculares, não buscamos uma "contraprova" entre fontes orais e fontes escritas. Ao invés disso, buscamos adensar a compreensão sobre as tensões entre o determinado exteriormente por meio das políticas e os modos de apropriação destas pelos docentes.

Ademais, o emprego de narrativas docentes tem sido frequente em estudos da área curricular (GOODSON, 2013; GOODSON; GILL, 2011; GOODSON et al. 2010), bem como na história da educação (BOSI, 1994; BRAGANÇA, 2012; DE SOUZA, 2011). Ivor Goodson (2013), por exemplo, combina estudos históricos e etnográficos como um modo de ampliar e aprofundar o entendimento do currículo, associando-se a tradições da antropologia, da sociologia, da fenomenologia e da hermenêutica. Apoiando-se em autores como Éclea Bosi (2003), Beatriz Sarlo (2005) e Moreira (2006) assumimos a memória como "recordação ativa do passado, por meio do qual se vislumbra a possibilidade de compreensão e de esclarecimento do passado como do presente" como assinala Moreira (2006, p. 10). 
Memórias e narrativas se entrelaçam na sustentação da análise empreendida no presente estudo, para auxiliar a compreensão de sentidos de autonomia docente no contexto fluminense. Inês Bragança (2008) destaca que as narrativas de professores não pretendem descrever a realidade, mas permitem acessar conhecimentos individuais e coletivos na medida em que potencializam movimentos de reflexão sobre as próprias experiências, teorias e práticas. Dessa maneira, mais que um momento de coleta de informação sobre suas vivências com as políticas atuais, o momento de ouvir é também um momento de troca em que tanto quem narra quanto quem escuta reflete sobre o contexto estudado.

Alguns autores (BOSI, 1994; BRAGANÇA, 2012) lembram que lançar mão da memória não se restringe apenas ao ato de "reviver" as experiências vividas, mas sim de reconstruir, ressignificar com as experiências de hoje, as do passado, utilizando-se dos materiais de que se dispõe no presente. Assim, esse aspecto se reveste de um caráter pedagógico da memória, uma vez que o fato de lembrar o passado implica em uma mudança de ponto de vista (BRAGANÇA, 2012). Para Goodson (2006) trabalhar narrativas e memórias explicita o poder atualizador da memória, bem como a possibilidade de se reconhecer no docente a consciência de seu potencial e a presença de sonhos que inspirem suas práticas e a construção de sua identidade profissional.

Assim sendo, tão importante quanto estudar os documentos que pretendem introduzir as políticas estudadas e de que maneira foram produzidos, é procurar entendê-los também no contexto em que esses documentos tomam forma de variadas maneiras. Como afirma Thompson (2002), é apenas no contexto da experiência viva, que as ideias podem se tornar consistentes e podem também ser testadas. Assim sendo, ouvir as experiências vividas por professores de Biologia da rede estadual parece crucial para compreender 0 tensionamento entre as políticas curriculares de ensino e avaliação e a autonomia docente e é partir delas que iremos analisar essas relações neste trabalho. 


\section{Metodologia}

A entrevista, como uma das formas de produzir dados qualitativos para a pesquisa, vem sendo largamente utilizada, sobretudo e quando se pretende entender as tensões dos contextos de ação curricular a serem pesquisadas. $O$ uso de entrevistas pode ser tornar valioso quando se precisa identificar práticas, valores e explicitar conflitos e contradições, permitindo ao pesquisador coletar indícios dos modos como cada um dos sujeitos entrevistados percebe e significa a sua realidade a fim de descrever e compreender a racionalidade que rege as relações que se estabelecem no interior de determinado grupo (DUARTE, 2004). Nesse processo, portanto, o pesquisador tenta analisar as subjetividades dos entrevistados ao procurar mobilizar suas memórias através de narrações sobre os fatos vividos e suas experiências.

Para mobilizar as memórias dos professores de Biologia e a partir delas compreender a influência das políticas curriculares e de avaliação nas escolas, é necessário reconhecer o protagonismo do professor e também aceitar que os docentes são sujeitos que disputam com grupos hegemônicos, oriundos do campo disciplinar, científico e também de outros setores da sociedade secretarias das redes de ensino, editoras, grupos empresariais, comunidades religiosas e familiares, etc. - que gradativamente têm se tornado mais fortes nas decisões curriculares. Nessa disputa, os docentes têm ocupado um lugar de subalternidade frente a esses grupos (SELLES e ANDRADE, 2016). Goodson (2006) enfatiza a centralidade do professor na prática curricular, denunciando sua costumeira secundarização na formulação de políticas de currículo. Por sua vez, Moreira e Silva (2002) rejeitam a neutralidade do currículo como uma simples seleção de conhecimentos a serem ensinados, pois sua produção implica relações de poder, visões de mundo e ideologias. Deste modo, a literatura insistentemente documenta que o currículo tem uma história, um contexto de elaboração que reflete a sociedade da época e o modo 
de pensar a educação (GOODSON, 1995; LOPES; MACEDO, 2011; MOREIRA; SILVA, 2002; SANTOS; 2012; SILVA, 2007).

Assim, durante a produção curricular muitas disputas se travam, e em diversos níveis de relações de poder, e o currículo não pode ser entendido como um conjunto homogêneo e neutro de conhecimentos, mas nele as visões de determinados grupos sociais se expressam ao adquirir maior legitimidade para selecionar conhecimentos e métodos (APPLE, 2002). Nem todos disputam com igual possibilidade as decisões sobre o que, quando e como ensinar e não causaria estranhamento no caso do estado do Rio. Ouvir a voz de professores de Biologia nessa produção curricular, nessas intrincadas relações de poder e de captura sobre o fazer docentes pode evidenciar sua influência nas seleções de sua própria disciplina escolar Biologia. Ou ainda, como vão modelando-a no confronto entre determinações, obediências e resistências

Inspirada por essas reflexões foram entrevistados docentes atuantes antes e depois da implantação do currículo mínimo e da avaliação externa da rede estadual, buscando explorar, a partir de suas memórias, como essas políticas podem ter interferido nos seus planejamentos, e em seu trabalho dentro de sala de aula. Cabe dizer que a escolha dos professores entrevistados ocorreu de forma totalmente voluntária por parte dos docentes, na medida em que a divulgação da necessidade de participantes para a pesquisa foi feita em uma rede social e participaram os professores que se mostraram interessados. Utilizamos um grupo dentro uma rede social que reúne alunos e egressos do curso de Licenciatura em Ciências Biológicas da Universidade Federal Fluminense. Deste modo, tornamos pública a necessidade de voluntários, professores de Biologia da rede estadual, para a participação na pesquisa para a qual seriam utilizadas entrevistas. Cinco professores responderam ao convite, mas neste artigo elegemos apenas as narrativas de dois deles.

As entrevistas foram vídeo-gravadas (utilizou-se a internet, via transmissão de áudio/vídeo) e versaram em torno do tema "Currículo Mínimo, Saerj e 
Autonomia dos professores", tomando como base as seguintes questões que versavam sobre: (i) sua experiência de trabalho com o currículo mínimo (ii) de que modo o currículo mínimo é levado em consideração no planejamento de suas aulas; (iii) sua experiência de trabalho com o SAERJ e em que medida o SAERJ é levado em consideração no trabalho com suas turmas. Foram exploradas também questões específicas sobre como entendiam a influência do currículo mínimo e do SAERJ/Saerjinho sobre a autonomia docente. Por fim, foi pedido que os professores discorressem sobre as políticas curriculares e de avaliação da rede estadual de modo geral.

Os dois professores entrevistados são identificados neste artigo, como Professor I e Professor II. O Professor I trabalha há três anos na rede pública estadual, onde possui duas matrículas de 16 horas, distribuídas em duas escolas. Em ambas as matrículas o professor leciona Biologia. O Professor II, por sua vez, é professor da rede estadual há oito anos, possui uma matrícula de 16 horas, já lecionou em quatro escolas diferentes durante sua trajetória como docente e, atualmente, trabalha em apenas uma escola. Apesar dos dois professores entrevistados possuírem menos de 10 anos de atuação como docentes, para os fins da presente pesquisa, se diferenciam por terem vivenciado momentos distintos das políticas aqui estudadas. O Professor I, ao entrar na rede em 2013, já encontra o Currículo Mínimo e o SAERJ/ Saerjinho implantados e funcionando. Já o Professor II, que entrou na rede em 2008, vivenciou o período antes da implantação, a transição e, atualmente, as políticas já em vigor. Na seção seguinte são apresentados fragmentos da transcrição dessas entrevistas, escolhidas a partir de uma análise de seu conteúdo. Visam destacar instâncias que permitem melhor compreender a relação do trabalho docente com as políticas curriculares e de avaliação escolar vigentes no Estado do Rio de Janeiro.

O Currículo Mínimo, o SAERJ/SaerJinho e o Tensionamento da Autonomia DOCENTE 
Os professores entrevistados possuem diferentes trajetórias na rede estadual de ensino do Rio de Janeiro. Enquanto o professor I passou a trabalhar nesta rede após a implantação do Currículo Mínimo e do Saerjinho, que ocorreu em 2011, o Professor II atua desde 2009, e, portanto, antes e depois dessas políticas chegarem à escola. Como docente há mais tempo e tendo vivenciado modos distintos de trabalho no interior de uma escola estadual, este professor destaca o estranhamento produzido pela alteração ocorrida entre os dois momentos de sua vida profissional: o primeiro descrito como "mais autônomo", para outro mais regulado por uma política produzida externamente.

No inicio não foi legal. Foi uma transição muito brusca para o que a gente tinha, uma realidade um pouco mais autônoma, de você conseguir escolher perante as características da sua turma específica o que você poderia aplicar, o que seria mais interessante, para [uma outra, com] um currículo que já vem pronto. Então, de cara foi bem difícil assim de adaptar... [Professor II]

No entanto, o estranhamento deste professor não pode ser entendido necessariamente como uma recusa a essas imposições curriculares. Ambos os docentes, ao narrarem suas experiências em relação à utilização do currículo mínimo, parecem tratá-lo atualmente como um "guia" para as suas práticas em sala de aula, conforme se pode evidenciar a seguir:

[o currículo mínimo] Dá um norte, para o professor, do que ele deve fazer de maneira que todas as escolas trabalham 0 mesmo conteúdo. Então, eu aqui em Friburgo, vou trabalhar um conteúdo que vai ser o mesmo conteúdo que você vai trabalhar aí em Niterói, São Gonçalo que... o outro colega meu vai trabalhar lá em Campo Grande... enfim todos os professores vão trabalhar o mesmo conteúdo o que significa que todos os alunos terão, "teoricamente", a capacidade igual de conhecimento. Terão [ acesso ao] mesmo conhecimento, independente do lugar [em] que você vai trabalhar. E eu acho isso uma coisa positiva, porque senão pode, "teoricamente", virar uma bagunça. Cada um [professor] vai dar o que acha importante, vai deixar de lado o que não acha [...]

[ Professor I]

É um norte que a secretaria [estadual] pensa [para] unificar as escolas desse jeito então. De um modo geral, a gente tenta seguir como uma linha né, mas nem sempre é possível. [...] ele [o currículo mínimo] passa a ser um norte, ele passa a ser um direcionamento. 
Às vezes você consegue atingir várias das metas que são prédeterminadas, mas muitas vezes não se consegue. $\mathrm{E}$ dentro da minha sala de aula eu acabo não tendo muita fidelidade a esse currículo, porque eu prezo mais pelo bem-estar dos alunos né. Pela maneira que eles vão ficar, o que eles vão entender, pelo o que eles vão aproveitar daquilo do que simplesmente seguir à risca um protocolo[...]

[Professor II]

Os depoimentos dos professores, longe de evidenciar uma aceitação plena do currículo mínimo, sugerem o tensionamento entre seus modos de apropriação do mesmo. Enquanto afirma que o utiliza como guia, o Professor II, no trecho acima, indica que não é o currículo que estará em primeiro lugar na hora de organizar e planejar suas aulas, apontando algumas dificuldades encontradas ao se trabalhar com o currículo escrito. O Professor I, embora pareça demonstrar sua concordância pela distribuição justa e equitativa do currículo para alunos de diferentes localidades, entendendo que a unicidade pode evitar a "bagunça" na seleção curricular de cada professor, parece também refletir sobre a inconsistência entre a "ordenação" e sua liberdade de decisão. Talvez por isso, destaca no trecho a seguir, que o currículo pode trazer alguns problemas no planejamento das aulas dependendo da escola em que o professor leciona.

Dependendo da sua escola, da sua direção, dos coordenadores pedagógicos, [o currículo mínimo] pode te engessar muito também e isso não é positivo, porque não dá brecha pra você [decidir], 'ó eu vou seguir esse conteúdo, mas vamos dar uma adaptadinha aqui, vamos dar uma mexidinha aqui', e é isso o que eu acho o ideal, é isso que eu tento fazer.

[Professor I]

A tensão que parecia estar negada na aceitação do currículo mínimo como uma solução que permitiria administrar eficiente e justamente a distribuição do conhecimento pela rede de ensino aparece vigorosa quando se colocam juntos currículo e avaliação. Em relação a este conjunto, a narrativa do Professor II mostra como o efeito controlador dessa combinação interfere no seu cotidiano escolar, na dimensão de uma decisão que parece reconhecer como sua. Por um lado, o docente aponta como essa relação pode influenciar, até mesmo na 
escolha das turmas em que cada docente irá lecionar, inclusive deslocando-o da disciplina (e nível de ensino) para a qual foi concursado, por discordar das regras impostas ou ser "rebelde" a elas nesse jogo. Por outro lado, reconhece o incômodo dessa imposição pela ausência de discussão sobre essas políticas, pois percebe-as como chegando "prontas" (leia-se, autoritariamente) ao ambiente escolar.

Eu já tive que lidar com essa cobrança [da secretaria estadual] de inclusive incluir o SAERJ como uma das avaliações, meio que não te dando muita opção. Você tendo que usar o SAERJ, o resultado do SAERJ, que não é uma obrigação do professor... ter que fazer a correção do SAERJ pra poder usar como um método de avaliação. Eu acho que até por eu ser meio rebelde com isso, acho que fui tirado dessas turmas de ensino médio [...] Porque assim, pra mim seria muito melhor dar aula pro ensino médio, eu que sou... a minha matrícula é em Biologia. Eu gosto mais da Biologia do que de Ciências, mas assim... eu prefiro ter mais liberdade do que ter que ficar sujeito a esse tipo de cobrança. Então eu acabo não achando ruim pegar as turmas de séries mais baixas por não ter tanta cobrança. Mas é de fato uma situação bem... é ....assim, não é questão de ser incomôda só, é uma questão, uma situação que não cabe, que não faz muito sentido porque existe uma cobrança por parte da direção que não faz ideia do que é o currículo. Simplesmente, ela [a direção] só quer que seja cumprido por causa do SAERJ. Não existe uma discussão sobre a razão do SAERJ ou se - SAERJ de fato avalia alguma coisa ou não. É uma coisa meramente imposta né, você recebe isso e não existe argumentação, não pode ser argumentado de alguma forma então acaba sendo uma coisa que perde o sentido né. A meu ver, poderia ter uma função muito interessante, mas se perde muito por causa dessas questões extremamente antidemocráticas. [Professor II]

A narrativa do professor II ilustra o esvaziamento de sua própria ação docente em uma das tarefas codificadas no exercício profissional docente. A "rebeldia" do professor não pode ser entendida como movida por negligência ou por descompromisso com seus alunos, haja vista que o mesmo docente havia declarado sua preocupação com os sucessos deles na avaliação: "eu prezo mais pelo bem-estar dos alunos né. Pela maneira que eles vão ficar, o que eles vão entender, pelo o que eles vão aproveitar ...”. Ou seja, o interesse dos alunos parece também dirigir sua rejeição, e o professor II ao vivenciar a interferência do controle externo, passa a ser punido naquilo que não estava disposto a negociar, qual seja, a docência em Biologia no ensino médio. 
Entretanto, prezando sua liberdade em detrimento do controle sobre a avaliação, ajusta-se às "turmas de séries mais baixas" abrindo mão de uma condição mormente mais valorizada no contexto escolar, ainda que denuncie a violência sobre sua autonomia.

Deste modo, vê-se que, dependendo do contexto de trabalho do professor, do quanto é possível negociar, essas políticas podem estar não só interferindo na autonomia do professor sobre quais conteúdos ensinar, mas até mesmo sobre a decisão relativa a quais séries esse professor pode ou não lecionar, uma vez que algumas realizam as avaliações externas e outras não. É possível observar então que a interferência dessas políticas não se restringe às salas de aula, mas ao ambiente escolar como um todo e às relações de poder que se encontram nesse ambiente.

\section{CONSIDERAÇÕES FINAIS}

Neste artigo, pretendemos compreender relações entre políticas curriculares que se associam intrinsecamente com a avaliação e modos de apropriação destas na produção curricular empreendida por docentes, utilizando entrevistas para a recolha de memórias desta produção. As narrativas dos dois professores de Biologia entrevistados parecem corroborar com o debate presente na literatura de que está em curso um tipo de racionalização sobre o trabalho docente que revitaliza o controle sobre o currículo. $O$ exame das narrativas também indica que os professores encontram cerceamentos constrangedores sobre as decisões que envolvem o seu próprio trabalho. $O$ detalhamento cada vez maior das propostas curriculares, sob a alcunha de "currículo mínimo", evidencia o controle do Estado. Obviamente o "estado" é entendido não como uma abstração, mas seu controle se refere a forças seletivas materializadas por sujeitos que, em vários níveis, centralizam determinadas decisões curriculares sobre o conhecimento considerado válido para a rede estadual. Longe de se circunscrever a uma listagem de conteúdos 
(ainda que esta exiba a pobreza da proposta estadual), o currículo mínimo tem como alvo as práticas docentes, afastando seus atores (e "autores", como prefere Luciano Mendes de Faria Filho) ${ }^{7}$ das esferas nas quais podem decidir sobre o desenvolvimento do seu trabalho. Ganha força então, a ideia do currículo como um guia a ser seguido, um "norte", uma solução higiênica e econômica que distribui equitativamente o conhecimento aos alunos e se instaura do exterior. Ao não ser produzido no interior do ambiente escolar, pelos atores que constroem seu cotidiano, já mostra a distância entre os que tomam as decisões e aqueles que devem "aplicá-las". Em outras palavras, reafirmam-se relações de poder de modo inequivocamente desigual, ainda que percebido por alguns (como um dos docentes entrevistados enunciou) como bem-vindo para manter a ordem e garantir a justa distribuição do conhecimento, finalidade reconhecida, inclusive, como dever da rede estatal.

A despeito dessa aparente aceitação de controle, das facilidades pedagógicas que o exercício profissional em escolas brasileiras possa sugerir, essa dimensão controladora é colocada em xeque quando confrontada com as avaliações que acompanham a implantação do Currículo Mínimo. É na dimensão das avaliações externas que o desconforto provoca uma reflexão mais atenta por parte do professor, pois elas reforçam ainda mais o controle do estado através da performatividade, sobre um domínio próprio da profissão docente. Como afirma Ball (2002), essa cobrança pelos resultados, pela efetividade, não resulta apenas em uma reforma educacional. Resulta também em uma reforma sobre o que é a educação e de qual é o papel do professor no processo educativo. Nesse contexto, o professor vê-se reduzido a apenas um instrutor, um aplicador dos conteúdos propostos pelo currículo e que serão cobrados pelas avaliações externas, que, hipoteticamente, mensuram a qualidade escolar. Do controle sobre o que deve ser ensinado, da dimensão da distribuição equitativa do conhecimento, retoricamente anunciada no documento oficial, é por meio de sua vinculação a essas avaliações, que se passa a regular o desempenho do profissional, a divulgar listagens e

${ }^{7}$ FARIA FILHO, L. M. Aula, autoria e reconhecimento: implicações para a pesquisa sobre os currículos da escola básica. Palestra proferida na PUC-Rio, 2015. 
ranqueamentos das escolas. Tais resultados expõem os professores bem sucedidos, ou melhor, os que se adaptam a esta estratégia regulatória que visa produzir identidades a serem reproduzidas: os melhores docentes, as melhores escolas, ou mesmo o melhor ensino de Biologia (SELLES e ANDRADE, 2016). Essas estratégias de controle por meio de ranqueamentos e de produção de identidades docentes, conforme adverte Thomas Popkewitz (2013), provocam exclusão dos docentes que a elas não se "ajustam".

Enfrentar essa discussão no momento atual do país, não apenas no Estado do Rio de Janeiro, mas, principalmente, em escala nacional com o surgimento da Base Nacional Comum Curricular (BNCC) de responsabilidade da SEB-MEC, sugere o quanto a reflexão acadêmica não se encontra desassociada politicamente, ou melhor, o quanto pode informar a diversas instâncias institucionais, não apenas à escola, como também à universidade. $O$ exame da questão trazido à discussão neste artigo pode antecipar alguns desdobramentos contidos na proposição da BNCC. Quais mudanças na concepção de educação e do ensino acompanharão o desenvolvimento de uma base nacional comum associada à aplicação de exames nacionais de larga escala por todo país? Qual será função social da escola em meio a essas políticas? E ainda, que reconfigurações podem ser aguardadas para o trabalho docente?

Pesquisas como as que examinam, de modo articulado, documentos curriculares escritos e fontes orais de docentes que atuam nas escolas sugerem a potência metodológica de tal empreendimento. Além disso, parecem instigar a realização de outras pesquisas que se disponham a ouvir mais atentamente aqueles que lidam com essas políticas no dia-a-dia das salas de aula das muitas escolas que se encontram em nosso país. Como sugere António Nóvoa (2011) essas pesquisas se propõem a reivindicar políticas que valorizem os professores, os seus saberes e os seus campos de atuação, que reforcem as culturas docentes, e que não transformem os professores numa profissão dominada por peritos ou pela indústria do ensino (NÓVOA, 2011, p. 
535). O exemplo já em vigor no Estado do Rio de Janeiro, e que parece se ampliar implacavelmente por todo país num futuro próximo, pode estar antecipando o que há vir em uma escala ainda maior, visto que a BNCC se dirige a cerca de 150 mil escolas públicas do país. Dessa forma, a discussão sobre a autonomia docente, longe de se assentar em um modelo idealizado desta autonomia, conforme discutem Selles e Andrade (2016), mostra-se atual e relevante para a construção de uma agenda de pesquisa educacional. Compreender como políticas curriculares de caráter unificado se associam a sistemas de avaliação de massa permite revisitar a discussão sobre a autonomia do trabalho docente e tonificá-la contra o enfraquecimento profissional.

\section{REFERÊNCIAS BibLIOGRÁFICAS}

APPLE, M. W. Trabalho docente e textos: economia política das relações de classe e de gênero em educação. Porto Alegre: Artes Médicas, 1995.

APPLE, M. W. El Conocimiento Oficial: la educación democrática en una era conservadora. Buenos Aires: Paidós, 1996.

APPLE, Michael W. A política do conhecimento oficial: faz sentido a ideia de um currículo nacional? In: SILVA, Tomaz Tadeu da.; MOREIRA, Antônio Flávio Barbosa. Currículo, Cultura e Sociedade. 11 ed. São Paulo: Cortez, $20027^{\mathrm{a}}$ ed.

BALL, S. J. Reformar escolas/reformar professores e os terrores da performatividade. Revista Portuguesa de Educação, v. 15, n. 2, p. 3-23, 2002.

BALL, S. J. Performatividade, privatização e o pós-Estado do bem-estar. Educação \& Sociedade, v. 25, n. 89, p. 1105-1126, 2004.

BOSI, E. O tempo vivo da memória: ensaios de psicologia social. Ateliê editorial, 2003.

BOSI, E. Memória e Sociedade: Lembranças de Velhos. 3a ed. São Paulo, Companhia das Letras, 1994.

BRAGANÇA, IF de S. Histórias de vida e formação de professores/as: um olhar dirigido à literatura educacional. Histórias de vida e formação de professores. Rio de Janeiro, Quartet/FAPERJ, p. 65-88, 2008.

BRAGANÇA, I.F.S. Histórias de vida e formação de professores: diálogos entre Brasil e Portugal. Rio de Janeiro: EDUERJ, 2012. 
CHERVEL, A. História das disciplinas escolares: reflexões sobre um campo de pesquisa. Teoria \& Educação, Porto Alegre, № 2, p. 177-229, 1990.

CONTRERAS, J. A autonomia de professores. $2^{-a}$ ed. São Paulo: Cortez, 327 p. 2012.

DOURADO, L. F; de OLIVEIRA, J. F. A Qualidade da Educação: Perspectivas e Desafios. Cad. Cedes, Campinas vol. 29, n. 78, p. 201-215, maio/ago. 2009

DE FARIA FILHO, L. M.; BERTUCCI, L. M. Contribuições de EP Thompson para uma história social da escolarização. Currículo sem Fronteiras, v. 9, n. 1, p. 10-24, 2009.

DE SOUZA, Elizeu Clementino. Territórios das escritas do eu: pensar a profissão-narrar a vida. Educação, v. 34, n. 2, 2011.

DUARTE, Rosália. Entrevistas em pesquisas qualitativas. Educar em revista, n. 24, p. 213-225, 2004.

GOODSON, I. Currículo: Teoria e História. Petrópolis, RJ: Vozes, 1995.

GOODSON, I. As políticas de currículo e de escolarização: abordagens históricas. Petrópolis, RJ: 2006.

GOODSON, I. et. Al. Narrative Learning. London: Routledge, 2010.

GOODSON, I.; GILL, S. Narrative Pedagogy. New York: Peter Lang, 2011.

GOODSON, I.F. Developing Narrative Theory. Life Histories and Personal Representation. Londo: Routledge, 2013.

LACLAU, E. \& MOUFFE, C. (2004). Hegemonia y estratégia socialista. Buenos Aires, Fondo de cultura econômica.

LOPES, A. C. e MACEDO, Elisabeth. Teorias de Currículo. São Paulo: Cortez, 2011.

MACEDO, E. Base Nacional Curricular Comum: novas formas de sociabilidade produzindo sentidos para educação. Revista e-Curriculum, São Paulo, v. 12, n. 03 p.1530 - 1555 out./dez. 2014.

MOREIRA, Antônio Flávio Barbosa. Prefácio. In: GOODSON, Ivor F. As Políticas de Currículo e de Escolarização. Rio de Janeiro: Vozes, 2006.

MOREIRA, A. F.; SILVA, T. T. da (orgs.). Currículo, Cultura e Sociedade. São Paulo: Cortez, 2002.

NÓVOA A. Formação de professores e profissão docente. In: Nóvoa, A, org. Os professores e sua formação. Lisboa: Publicações Dom Quixote; p.1533. 1997.

NÓVOA, António et al. Pesquisa em educação como processo dinâmico, aberto e imaginativo: uma entrevista com António Nóvoa. Educação \& realidade, v. 36, n. 2. Porto Alegre - RS, maio/agosto, p. 533-543, 2011.

POPKEWITZ, Thomas S. Números em grade de inteligibilidade. Dando sentido à verdade educacional. In: TURA, Maria de Lourdes Rangel; GARCIA, Maria Manuela Alves (org.). Currículo, Políticas e Ação Docente. Rio de Janeiro: EdUERJ, p. 19-50, 2013. 
SANTOS, T.C. A reforma curricular do curso de Letras da Universidade Federal do Acre na década de 1980: entre ditos e escritos. Tese (Doutorado em Educação) - Universidade Federal Fluminense, 2012.

SILVA, Tomaz Tadeu da. Documentos de identidade: uma introdução às teorias do currículo. Belo Horizonte - MG: Autêntica, 2007.

SARLO, B. Tempo Passado. Cultura da Memória e Guinada Subjetiva. São Paulo: Companhia das Letras, 2005.

TARDIFF, M. Saberes, tempo e aprendizagem do trabalho no magistério. In: Saberes Docentes e Formação Profissional. 17 ed - Petrópolis, Rj: Vozes, 2014.

THOMPSON, E. P. A miséria da teoria. Rio de Janeiro:Zahar, 1981.

THOMPSON, E. P. Educação e experiência. In: THOMPSON, E. P. Os Românticos. Rio de Janeiro: Civilização Brasileira, 2002.

THOMSON, A. Recompondo a memória: questões sobre a relação entre história oral e as memórias. Projeto História. Revista do Programa de Estudos Pós-Graduados de História. e-ISSN 2176-2767; ISSN 0102-4442, v. $15,1997$. 